\title{
Synthesis and Integration of Energy Relate Tropospheric Chemistry Research
}

\section{Final Report}

This is the final report summarizing the results in all of the tasks covered under DOE Grant ER63104 for 2004 to 2005 (From March 2001 to March 2005). The scope of work under the grant covers five areas (tasks): 1 . Analysis and interpretation of scientific studies relating to tropospheric air chemistry; 2. Characterization of source attribution research; 3. Preparation of the 2002 (2003) NARSTO particulate matter (PM) Assessment; 4. Survey of atmospheric science-human exposure research; and 5. Investigation of carbonaceous emissions from energy (and other) sources. Activities in each of these areas is discussed in the subsequent sections, including results, mainly as products in the literature.

\section{Task 1. Analysis and Interpretation of Scientific Studies}

During the period of the DOE grant, the work done under this task involved both Dr. Hidy of Envair/Aerochem, and Dr. Mueller of Tropochem. The work involved participation in the NARSTO leadership team [The Executive Steering Committee (Mueller and Hidy, ex-officio)], and co-chair of the Analysis and assessment Team (Hidy)]. NARSTO is a North American cooperative involving conduct and synthesis of "policy relevant" air quality research in the United States, Canada and Mexico.

Dr. Hidy and Dr. Mueller gave primary attention was devoted to (a) planning and development of commitments for NARSTO projects, for various workshops and member meetings, and for the design and conduct of major state-of-science assessments (b) overviews of NARSTO's evaluation and use of results from a number of NARSTO supported field experiments and (c) guidance and participation in two NARSTO assessments (particulate matter-PM [also Task 3] and emission inventories). The two major assessment reports include the PM assessment (McMurry et al., 2004) and the Emissions Inventory Study (NARSTO, 2005). These two reports have been distributed to NARSDTO stakeholders and members, as well as major academic and public libraries across North America.

The emissions inventory state of science and technology assessment was prepared in 2004-2005, and was published in 2005 (NARSTO, 2005). In its final stages this assessment was edited extensively based on external reviewer comments. A summary of this assessment was published in the Journal of Air and Waste Management in 2006 (Miller et al., 2006). In part, this assessment was motivated by the 2003 NARSTO workshop on innovative methods for emission inventory development (e.g., Hidy et al., 2004).

The NARSTO planning effort in 2005 resulted in a decision by this group to pursue a new assessment of scientific needs to support the concept of multi-pollutant air quality management, as proposed in a recent NRC report (NRC, 2004). This proposal was accepted by the members of NARSTO, and is to be implemented in 2006, with an 
incorporation of the concept of accountability in pollution management (as defined in NARSTO, 2003).

In addition to The NARSTO support activities Dr. Hidy and Dr. Mueller participated in, and contributed to relevant conferences organized by (a) the Air and Waste Management Association. Including annual meetings (2001-2004), and the Conference on Visibility [October 2004], and (b) the American Association for Aerosol Research (AAAR) PM2.5 Conferences in 2003 and 2005 (e.g., Hidy et al, 2003). At these meetings, presentations were given on various aspects of tropospheric aerosol chemistry (See also Task 5).

In addition participation in ad hoc meetings included two carbon conferences, EPA supersites investigator meetings, and other stakeholder meetings on ozone and particulate matter issues (also Task 2). Dr. Hidy also participated as a member of the 2004 DOE Atmospheric Science Program review to recommend major changes in goals, shifting from atmospheric chemistry and tropospheric meteorology to global scale climate science (BERAC, 2004).

One of the features of tropospheric chemistry which is important to considerations of air quality and climate science is the ramifications of phenomena taking place on multiple spatial and temporal scales. Multiple scale processes and effects have been recognized for sometime, but have not been fully appreciated in relation to air quality management until recently. As a review of the relevant science, Dr. Hidy published a paper on the important of multi-scale pollution phenomena under this grant (Hidy, 2002).

Another concern derived from tropospheric chemistry involves the processes of chemical deposition. The phenomenon of wet and dry deposition of acidic species is well known in parts of North America and Europe. However, relatively little effort has been made to synthesize the literature on snowpack chemistry. As an outgrowth of earlier work on snowpack chemistry in the Rocky Mountain region, Dr. Hidy reviewed and interpreted the literature on this subject, and published a major review on air pollution and snowpack chemistry (Hidy, 2003).

As part of the investigations of tropospheric chemistry, some work was devoted to review and evaluation of North American "background" aerosols in the light of global aerosol distributions. The survey and evaluation of the literature between 1990 and 2000 resulted in a contribution, which added certain definitions for natural background, compared with baseline conditions across much of North America. The resulting paper described refined baseline conditions mainly from the long term rural and remote area data record of the IMPROVE network in the US. A baseline condition for PM2.5 mass concentrations, sulfate and carbon levels was prepared for zonal bands across the US and southern Canada. These results were presented at the AWMA Visibility Conference in 204, and reported in Hidy and Blanchard (2005).

While the effort to review and evaluate the results and conclusions of global scale studies of particulate matter remained incomplete, the results of the literature survey and 
review sponsored by this grant has resulted in a new review paper covering the current global scale patterns for fine particle mass, sulfate and carbon concentrations (Hidy, 2006).

\section{Task 2. Characterization of Source Attribution Research}

During this period, monitoring continued of results from major field studies, relating to characterizing source attribution of PM. Major studies have included the EPA national supersites program, the Houston 2001 experiment, ARIES-SEARCH, MARCHAtlantic, NARSTO-NE, BRAVO, the SJVAQ studies, Vancouver, the DOE-NETL Upper Ohio River Valley Study, the DOE-Consolidated Coal Corporation Steubenville Study, the planning for a major study in 2006 in Mexico City, and various U.S./border studies from El Paso to San Diego.

These and other field experiments appear to have produced sufficient results now that they can be reviewed more or less in toto for their significance in developing new information about atmospheric chemistry, pollution and the linkages between chemistry and sources of pollution that have been (or can be) applied to inform policy makers. Planning for this grant included a review of current field programs to be co-authored by Dr. Mueller and Dr. Paul Solomon. A review of results from recent programs such as the EPA supersites program is ongoing. Additional coverage is derived from the literature as part of the investigations, which characterize aerosol particles on a large, global scale (e.g., Hidy 2006).

The NARSTO assessment on emission inventories, included a discussion of source attribution methods from ambient air quality data. The development of methods involving inverse source-receptor modeling, and receptor modeling to evaluate the consistency and quality of emission inventory data, has led to substantial improvement of the inventories for volatile organic compounds and for particulate matte (NARSTO, 2005).

An interesting feature of source attribution research during this period has emerged in work linking apparent particulate source contributions with population health effects. This method, exemplified by the work of Laden et al. (2000) involves the use of factor analysis to identify apparent sources or source classes. The factors emerging from the factor analysis (e.g. positive matrix factorization-PMF) are then used in a regression model to link the factors with health endpoints such as total mortality of mortality from cardiovascular disease. The publication of Grahame and Hidy (2004) comments on the pitfalls of using this method for interpretation of source-health effects relationships.

Additional discussion of the strengths and weakness of the factor-regression method is reported in Schlesinger et al. (2006). \{See discussion below in Task 4). 


\section{Task 3. Participation and Preparation of the NARSTO 2002 (2003) PM Assessment.}

As noted above, the PM assessment was basically completed in 2003. The report was then edited extensively and published as a book by Cambridge University Press in 2004 (McMurry et al., 2004). According to representatives of North American national governments, this assessment has been widely distributed to managers responsible for air quality management. The monograph has been exceedingly useful in educating these people about the complexities of tropospheric aerosol chemistry, and its significance to air quality management practice.

\section{Task 4. Human Exposure Research on PM2.5.}

An important aspect of air quality management is the linkage between air chemistry and human health effects. Essentially this linkage is the driver for the management process in all three nations of North America. Technically the linkage is facilitated through an exposure and dose-response relationship for pollutant gases and particles. The complexity involved in exposure measures concerns the fact that people in North America, especially the US and Canada tend to spend the majority of their time indoors. The question of exposure to outdoor, ambient particle concentration was dealt with in the NARSTO PM assessment (McMurry et al., 2004). Chapter 2 deals with this subject. This chapter was written in large part by Dr. Roger McClellan. Much of his writing was sponsored in part by funding from this grant.

Exposure to chemical constituents in fine particles was also the subject of the paper of Grahame and Hidy (2004). The criticized the incomplete analysis of Laden et al. (2000) which basically misinterpreted results of a factor analysis identifying sources of pollution in the six cities study. Careful examination of their results linking apparent sources to mortality determined in the six cities resulting from exposure to air pollution provided an alternative explanation for sulfate sources. Only in one city (Boston) were significant results to exposure of sulfate found. The exposure to sulfate was originally attributed to a regional pollution component identified with long range transport of sulfur from coal combustion. As an alternative, the data could be explained by a local Boston source of residual oil combustion from large power plants around the city.

A supplemental task was added to this grant in 2005 to prepare a major review of the current epidemiologic and toxicologic literature relating the chemical composition of ambient concentrations of fine particles $\left(\mathrm{PM}_{2.5}\right)$ to apparent human health effects. This review was conducted under DOE Office of Fossil Fuels sponsorship, and published as a major review paper in Inhalation Toxicology (Schlesinger et al., 2006).

The report indicated the strengths and weaknesses of evidence associated certain components of PM2.5 to health endpoints. Of particular interest are possible relationships to components that derive from fossil fuel combustion, such as airborne sulfate or carbon. The Schlesinger et al. paper reviewed both the contemporary epidemiologic and toxicologic evidence indicating apparent relationships between such $\mathrm{PM}_{2.5}$ components and health consequences. Although the literature is expanding, the results from different 
studies yield ambiguity with regard to specific PM components and health effects. These results recently have been elaborated in a recent paper of Reiss et al. (2006) specifically addressing the role of exposure to ambient particulate sulfate and nitrate in exacerbating adverse health effects. In this latter paper, the evidence to date, suggests that sulfate exposure per se has little influence on human health, but may be more significant in the presence of dissolved transition metals such as V or Ni (see also Grahame and Hidy, 2004). The results to date implicating nitrate exposure are too limited to make any conclusions.

\section{Task 5. The Nature and Potential Importance of Carbonaceous Emissions from Energy Sources}

Of particular interest for this task is the carbon released from major fossil fuel power plants. Carbon in the form of black or elemental carbon (BC) and organic carbon (OC) have been found to be a fraction of ambient $\mathrm{PM}_{2.5}$ that is comparable with sulfate concentrations. This observation is consistent in samples of ambient aerosols taken throughout the eastern US. In work partially sponsored by this grant, Edgerton et al. (2003) reported results from a sample of 15 coal-fired plants and an analysis of ambient data taken in the Southeast which suggested that the total carbon from such plant per unit mass of $\mathrm{PM}_{2.5}$ emitted is very small in normal operations, and is a very small part of the carbon found in ambient particles.

These results has largely been confirmed by parallel work of Bond et al. (2004), and a limited intercomparison reported by England et al. (2007). One apparent anomaly noted by the latter authors is emissions sampling done on a lignite fired plant in Texas, which appears to indicate a substantial amount of carbon emissions occur from this plant. The authors of this reported work, however, indicated that the uncertainty in sampling from this Texas plant was very high, based on the stack testing method used. Thus the principal evidence to date indicates that coal fired plants in normal operation are not large carbon sources. The carbon found in aerosol particle then evidently derives from other sources, including motor vehicle and railroad transportation, and vegetation fires.

The approach to identification of anthropogenic and natural source contributions to $\mathrm{PM}_{2.5}$ carbon concentrations, sponsored by work in this grant, was previously discussed. The method proposed uses a combination of conventional carbon measurements, and sampling for ${ }^{14} \mathrm{C}$ and ${ }^{12} \mathrm{C}$ isotope measurements. This method was proposed and published by Hidy et al. (2004). While this proposal has not been implemented, it does provide a comprehensive means of creating a mass balance approach for gaseous and particulate carbon from fossil and modern sources. No attempt has been made to date to actually achieve this result.

Dr. Hidy's knowledge of emission inventories as well fossil-fueled power plants operations provided the basis for a critique of the DOE (and other sponsored) fossil energy programs aimed at developing $\mathrm{CO}_{2}$ emission control technologies. Elements of the critique are reported in chow et al. (2003). 
Plans in 2004 called for completion of a manuscript for publication, describing the results of the power plant sampling program. At this time, this manuscript is incomplete pending the authors' coordination to complete the project. However, the salient results from this and other work characterizing carbon emissions was included in the NARSTO emissions inventory report (NARSTO, 2005).

\section{Summary}

This DOE grant has been productive in supporting a variety of work relating to tropospheric chemistry, sources of airborne particulate matter and related potential health effects. This work was reported primarily in terms of various reviews and data evaluation for publication in the technical literature.

The grant supported Dr. Hidy and Dr. Mueller in their activities for NARSTO. NARSTO has continued to be very active in providing its North American stakeholders with assessments of science and technology on various topics. Given support of its constituents, NARSTO is expected to continue its assessment efforts into the late 2000s with a new effort evaluating the current state of knowledge relating to the concept of accountability in air quality management, and the approach to management using a multipollutant paradigm. 


\section{References}

Bond, T. C. et al. A technology-based global inventory of black and organic carbon emissions from combustion. J. Geophys. Res. 109: D14203 (2004).

*Chow, J.; Herzog, A.; Benson, S.; Hidy, G.; Gunter, W.; Penkala, S.; White, C. Separation and capture of CO2 from large stationary souces and sequestration in geological formations. J. Air \& Waste Manage. Assoc. 53, 1172-1182.

*Edgerton, E. S.; Mueller. P. K.; Monroe, L. S.; Jansen, J.J.; Waid, C. J. “Particulate Carbon Emissions from Coal Fired Power plants: Stack Testing and Field Observations.” Paper P01-02 in Abstracts, Particulate Matter: Atmospheric Sciences, Exposure and the Fourth Colloquium on PM and Human Health. American Assn. for Aerosol Research. Pittsburgh, PA, 2003.

England, G.; Watson, J.; Chow, J.; Zielinska, B.; Loos, K.; Hidy, G. M. Dilution-based sampling from stationary sources: Part 2. Gas-fired combustors compared with other fuel-fired systems. J. Air \& Waste Manage. Assoc. 57, 79-94 (2007).

*Grahame, T.; Hidy, G. M. Using factor analysis to attribute health impacts to particulate pollution sources. Inhalation Toxicology 16 (suppl 1), 143-152 (2004).

*Hidy, G. M. Multiscale impact of PM air quality from energy sources. Energy and Fuels 16, 270-279 (2002).

*Hidy, G. M. Snowpack and precipitation chemistry in high-elevation regimes. Atmos. Environ. 37, 1231-1242, (2003).

*Hidy, G. M.; Blanchard, C. L. The North American background aerosol and global aerosol variation. J. Air \& Waste Manage. Assoc. 55, 265-272 (2005).

*Hidy, G. M.; Pace, T.; Niemi, D. "North American Emissions Inventories Applicable to Management of Airborne Particulate Matter (PM).” Paper P01-02 in Abstracts, Particulate Matter: Atmospheric Sciences, Exposure and the Fourth Colloquium on PM and Human Health. American Assn. for Aerosol Research. Pittsburgh, PA, 2003.

*Hidy , G. M.; Eatough, D. J.; Klouda, G. Design scenario for the radio-isotopic estimation of the biogenic component of airborne particles. J. Air \& Waste Manage. Assoc. 54, 600-613 (2004).

*Hidy, G. M.; Mobley, J. D.; Cadle, S. H. Innovative methods for emission inventory development and evaluation: Workshop synthesis. Environ. Manager 14, November (2004). 
Laden, F.; Neas, L.; Dockery, D.; Schwartz, J. Association of fine particulate matter from different sources with daily mortality in six U.S. cities. Env. Health Perspectives 108, 941-947 (2000).

*McMurry, P.; Shepherd, M.; Vickery, J. (eds.). Particulate Matter Science for Policy Makers. Cambridge University Press, Cambridge, 2004, especially Ch. 4.

*Miller, C. A.; Hidy, G. M.; Hales, J.; Kolb, C.E.; Werner, A. S.; Haneke B.; Parrish, D.; Frey, C.; Rojas-Bracho, L.; Deslauriers, M.; Pennell, W.; Mobley, J. D. Air emission inventories in North America: A critical assessment. J. Air \& Waste Manage. Assoc. 56, 1115-1129 (2006).

*NARSTO. Improving Emission Inventories for Effective Air Quality Management Across North America. NARSTO-05-001. NARSTO Management Coordinator's Office, Kennewick, WA, 2005, especially Chapter 6.

(US) National Research Council. Air Quality Management in the United States. National Academy Press, Washington, DC, 2004.

Reiss, R; Anderson, E.; Cross, C.; Hidy, G.; Hoel, D.; McClellan, R.; Moogavkar, S. Evidence of health impacts of sulfate and nitrate containing particles in ambient air. In press, Inhalation Toxicology (2006).

*Schlesinger, R.; Kunzli, N.; Hidy, G..; Jerrett, M.; Gotschi, T. The health consequences of PM exposure: Integration and coherence of toxicological and epidemiological inferences. Inhalation Toxicology 18, 1-31 (2006).

* Sponsored entirely or in part by this DOE grant. 